\title{
Appendix B: participant background
}

The experiment contained a demographic question asking participants for their location. The table below collapses responses based on region.

$\begin{array}{ll}\begin{array}{l}\text { Number of } \\ \text { participants }\end{array} & \text { Region } \\ 7 & \text { Île-de-France } \\ 7 & \text { Pays de la Loire } \\ 6 & \text { Auvergne-Rhône-Alpes } \\ 1 & \text { Grand Est } \\ 1 & \text { Nouvelle-Aquitaine } \\ 1 & \text { Bourgogne-Franche-Comté } \\ 1 & \text { Hauts-de-France } \\ 1 & \text { Normandy } \\ 1 & \text { Occitanie } \\ 1 & \text { "France" (participant didn't specify) }\end{array}$

